REENCONTRO DE BALANOGLOSSUS GIGAS FR. MULLER NO LITORAL BRASILEIRO*

\title{
Paulo Sawaya
}

(Departamento de Fisiologia Geral e Animal - Universidade de São Paulo - Caixa Postal 2926).

Com 2 figuras

Em 1898 o DR. HERMANN VON IHERING, o saudoso diretor do Museu Paulista, ao traçar o necrológio de FRITZ MULLER, teve a feliz idéia de publicar as notas referentes às suas investigaçổes no litoral de Santa Catarina, até então inéditas.

Dêste modo chegou até nós o interessante relatório de FR. MULLER (1898, pg. 35) em que nos conta a descoberta e a captura do famoso Balanoglossus gigas (Fig. 1), assim por êle denominado por causa do seu tamanho excepcional. O animal, diz o célebre naturalista, media $1,5 \mathrm{~m}$ de comprimento, podendo chegar a $2,5 \mathrm{~m}$.

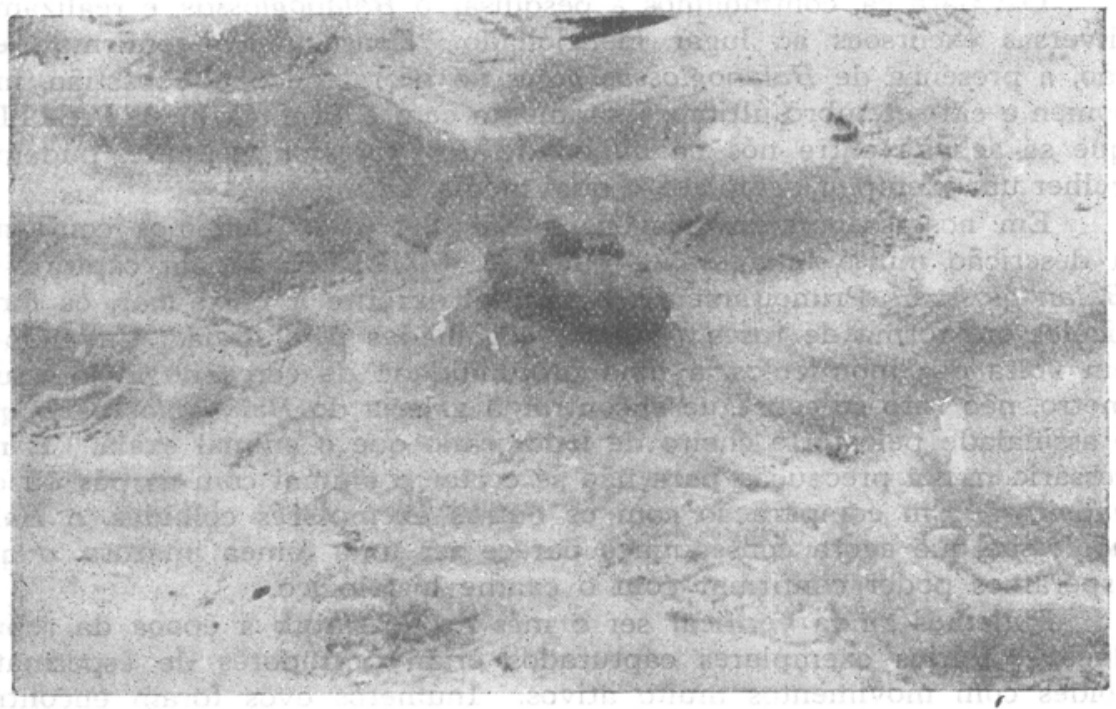

Segundo o referido relatório, FR. MULLER encontrou o primeiro exemplar em Agosto de 1884, no lugar denominado Saco da Armação,

(*) Este trabalho foi realizudo, em grande parte, graças ao auxílio dispensado pela - Comissão de Pesquisa Científica, da Universidade de São Paulo, sob a presidên7 G cia do Prof. Dr. Ernesto de Souza Campos, a quem muito agradecemos. 
no Estado de Santa Catarina. Em outra viagem, realizada de Janeiro a Fevereiro de 1885, ao local chamado Armação da Piedade, no mesmo Estado, conseguiu FR. MULLER capturar exemplares.

Daí para cá, pelo menos na literatura disponível, não nos foi dado achar quaisquer informaçôes sôbre a ocorrência posterior dêsse interessante animal no litoral brasileiro.

Acontece, porém, que em Setembro de 1948 o Prof. W. BESNARD, Diretor do Instituto Paulista de Oceanografia, em uma de suas excursões ac litoral de Sã̃o Paulo, notou sinais característicos da presença do Balanoglossus na praia chamada do Tôpo, ao sul da cidade de São Sebastião. Com grande esfôrço, auxiliado por alguns camaradas, conseguiu retirar da praia, partes do animal, as quais nos enviou para estudo. Verificámos desde logo tratar-se de um Enterapneustá, possivelmente do Balanoglossus.

Quasi ao mesmo tempo em que o Prof. BESNARD realizava a sua excursão ao referido local, achavamo-nos também efetuando pesquisas na praia de Bertioga. De volła, houve uma reunião conjunta do pessoal do Instituto Paulista de Oceanografia e do Departamento de Fisiologia Geral e Animal, para comentário dos resultados ob idos. Nessa ocasião, o Prof. W. BESNARD teve oportunidade de referir-se ao interessante achado, entregando-nos então os fragmentos do animal retirado da praia do Tôpo.

Daí para cá, continuámos a pesquisar o Balanoglossus, e realizamos diversas excursões ao lugar mencionado. Conseguimos confirmar, então, a presença de Balanoglossus gigas no litoral de São Sebastião, mas somenie em setembro último, juntamente com o Prof. C. F. A. PANTIN, que se achava entre nós na qualidade de Professor visitante, pudémos colher um exemplar completo, o qual media $1,80 \mathrm{~m}$.

Em nossas inúmeras viagens a São Sebastião pudemos confirmar a descrição muiso interessante que FR. MULLER dá, da captura do Balanoglossus. Primeiramente, notam-se, durante a baixa-mar, os montículos em forma de rosca (Fig. 2) espalhados pela praia. Cavando-se em volta dos montículos, a uma profundidade de cêrca de meio a um metro, não raro se consegue encontrar a galeria do Balanoglossus, o que é assinalado pelo forte cheiro de iodoformio que o animal exala. E necessário muita precaução para não se cortar o animal com as pás ou cayadeiras. Em comparação com os outros exemplares colhidos, o Balanoglossus que agora conseguimos parece ser uma fêmea imatura, o que esperamos poder confirmar com o exame histológico.

Pudemos ainda verificar ser o mês de Setembro a época da reprodução. Vários exemplares capturados eram portadores de espermatozóides com movimentos muito ativos. Inúmeros ovos foram encontrados que já apresentavam a membrana de fecundação.

O exame dos exemplares trazidos para o laboratório mostrou tratar-se realmente do Balanoglossus gigas FR. MULLER conforme SPENGEL o descreveu (1893, pg. 158). Este autor, que recebeu o material enviado por FR. MULLER, deu-lhe o nome de Ptychodera gigas SPENCEL 1893. Na sua moderna revisão dos Enteropneutas, VAN DER 
HORST 1939, pg. 717) coloca Ptychodera gigas SPENCEL na sinonímia de Balanoglassus gigas FR. MULLER e DAWIDOFF (1948, pg. 373) ao tratar das dimensões dos Enteropneustas assinala Bàlanoglossus gigas, dà América do Sul, ccmo sendo o maior.

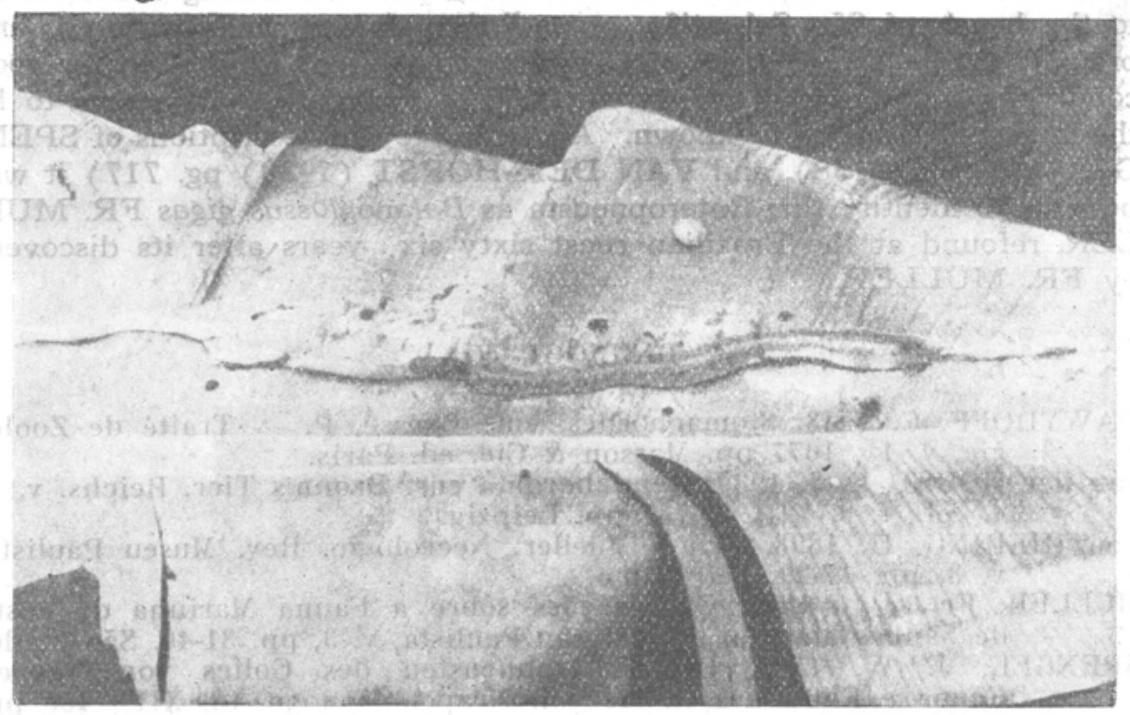

As características do nosso material concordam com as descrições de SPENGEL (1.c.) e de VAN DER HORST (1.c.), pelo que julgamos tratar-se realmente de Balanoglossus gigas FR. MULLER.

$\mathrm{O}$ estudo do valioso material colhido acha-se em andamento e esperamos poder confirmar esta determinação.

Seja-nos permitido agradecer aqui ao Prof. W. BESNARD, que com seu excepcional interêsse pelas pesquisas da fauna marinha brasileira nos possibilitou a continuação das investigações encetadas ha sessenta e seis anos pelo sempre lembrado naturalista de renome universal, FRITZ MULLER.

\section{SUMMARY}

Re-finding of Balanoglossus gigas FR. MULLER on the brasilian sea shore.

Balanoglossus gigas, the giant Enteropneusta, has been described for the first time by Fritz Muller in his notes collected and published by Dr. HERMANN VON IHERING (1898, pg. 35). FR. MULLER found the Balanoglossus on the coats of the State of Santa Catarina in 1884. Once again in 1885 several specimens of that animal were captured by FR. MULLER in the same place. Since that time up to now no references on the occurrence of this animal have been found in the zoological bibliography. 
During the spring of 1948 Prof. W. BESNARD, Director of he Instituto Paulista de Oceanografia saw some signals indicating the existence of Balanoglassus at the beach of São Sebastião, State of São Paulo.

From 1948 to now several attempts have been made to catch the animal alive and complete. On the last September during a short visit to the beach of São Sebastião one Balanoglossus was captured and brought to the Department of General and Animal Physiology in good conditions. The animal measured $1.80 \mathrm{~m}$ in length. It seems to be the largest Balanoglossus known. According to the descriptions of SPENGEL (1893, pg. 158), and VAN DER HORST (1939) pg. 717) it was possible to identify this Enteropneusta as Balanoglossus gigas FR. MULLER, refound at the Brazilian coast sixty six years after its discovery by FR. MÜLLER.

\section{BIBLIOGRAFIA}

DAWYDOFF, C. 1948, Stomachordes, em: Grassé, P. -.. Traité de Zoologie, v. 11. 1077 pp. Masson \& Cie. ed. Paris.

van der HORST, C. J. 1939, Hemichordata em: Bronn's Tier. Reichs. v. 4, $4 .^{n}$ pt., f. 6 , XIII +737 pp. Leipzig.

von IHERING, H. 1898, Frit Mueller. Necrológio. Rev. Museu Paulista, v. 3 , pp. 17-29. São Paulo.

MÚLLER, Fr. - 1898, Observações sôbre a Fauna Marinha da costa de Santa Catarina. Rev. Museu Paulista, v. 3, pp. 31-40. São Paulo.

SPENGEL, J. W. 1893, Die Enteropneusten des Golfes von Neapel. Fauna e Flora des Golfes von Neapel. Monogr. 18, XII + 758 pp. Berlin. 